\title{
Ice water content of Arctic, midlatitude, and tropical cirrus - Part 2: Extension of the database and new statistical analysis
}

\author{
A. E. Luebke ${ }^{1}$, L. M. Avallone ${ }^{1}$, C. Schiller ${ }^{2, \dagger}$, J. Meyer ${ }^{2}$, C. Rolf ${ }^{2}$, and M. Krämer ${ }^{2}$ \\ ${ }^{1}$ University of Colorado, Laboratory for Atmospheric and Space Physics, Boulder, Colorado, USA \\ ${ }^{2}$ Forschungszentrum Jülich, Institut für Energie und Klimaforschung 7, Jülich, Germany \\ ${ }^{\dagger}$ deceased 3 March 2012
}

Correspondence to: A. E. Luebke (anna.luebke@ colorado.edu)

Received: 31 October 2012 - Published in Atmos. Chem. Phys. Discuss.: 15 November 2012

Revised: 24 May 2013 - Accepted: 28 May 2013 - Published: 8 July 2013

\begin{abstract}
Ice clouds are known to be major contributors to radiative forcing in the Earth's atmosphere, yet describing their microphysical properties in climate models remains challenging. Among these properties, the ice water content (IWC) of cirrus clouds is of particular interest both because it is measurable and because it can be directly related to a number of other radiatively important variables such as extinction and effective radius. This study expands upon the work of Schiller et al. (2008), extending a climatology of IWC by combining datasets from several European and US airborne campaigns and ground-based lidar measurements over Jülich, Germany. The relationship between IWC and temperature is further investigated using the new merged dataset and probability distribution functions (PDFs). A PDF-based formulation allows for representation of not only the mean values of IWC, but also the variability of IWC within a temperature band. The IWC-PDFs are observed to be bimodal over the whole cirrus temperature range. This bimodality is also found in ice crystal number PDFs and might be attributed to different cirrus formation mechanisms such as heterogeneous and homogeneous freezing.
\end{abstract}

\section{Introduction}

Cirrus clouds are ice clouds found in the upper troposphere at altitudes where temperatures range from about $235 \mathrm{~K}$ to $185 \mathrm{~K}$. They have been observed to cover close to $40 \%$ of the Earth at any given time, with the greatest coverage at the tropics and along the midlatitude storm tracks (Wylie and Menzel, 1999). Although there is considerable research on cirrus clouds, the 2007 Intergovernmental Panel on Climate Change (IPCC; Forster et al., 2007) report says little about them, focusing mostly on their interaction with aircraft emissions, another area in which very little is known.

Cirrus clouds have the ability to both trap infrared terrestrial radiation and reflect solar radiation. Therefore, they are able to produce either a warming or a cooling effect on the Earth, depending on the balance between these two processes. The microphysical properties of an individual cirrus cloud, such as the cloud particle sizes (Liou et al., 2008) and the crystal habits (van Zadelhoff et al., 2007), contribute to whether absorption or reflection will dominate for a particular cloud. Determining the exact role of cirrus in the radiation budget of the atmosphere is difficult, however, owing to the assortment and variability of the microphysical, and thus radiative, properties involved, as well as the current lack of understanding of how and why some of those variations occur.

One of the microphysical properties of cirrus that is essential for better describing their radiative role is ice water content (IWC) (Liou et al., 2008). IWC is related to particle size and extinction, both of which are used to determine the radiative properties of a cirrus cloud. Currently, it is known that the IWC of cirrus varies over at least six orders of magnitude (from $10^{-3}$ ppmv to $10^{3} \mathrm{ppmv}$ ) and is influenced by factors such as the water vapor content of the air and temperature (Schiller et al., 2008). A few studies have provided data to demonstrate how IWC in cirrus varies. For example, data obtained with a millimeter-wave cloud radar at the Atmospheric Radiation Measurement (ARM) Climate Research Facility (ACRF) in Oklahoma was used to document the 
macrophysical and microphysical properties of cirrus clouds over the site for six years. The results are reported by Mace et al. (2006) and reveal the relationships between atmospheric conditions, such as the vertical velocities, and cloud properties, such as IWC. Though the dataset is large and spans several years, it covers only a single location. In the results of a similar project by Sassen and Campbell (2001), the authors note that, since the formation of clouds results from weather processes, their properties will vary across the planet, thus stressing the importance of obtaining datasets with global coverage.

While efforts have been made to obtain more comprehensive datasets through projects such as the Cirrus Regional Study of Tropical Anvils and Cirrus Layers - Florida Area Cirrus Experiment (CRYSTAL-FACE), logistical considerations dictate that a particular campaign focuses on a specific geographic region (e.g., the tropics, midlatitudes, or poles) and there is little to no overlap. Schiller et al. (2008) created an extensive dataset of IWC values by combining data from ten European airborne field campaigns. In this paper, we report the extension of that dataset by including measurements from four US field campaigns of similar design.

One of the most common ways to parameterize ice cloud properties in models is to use IWC (Heymsfield and Platt, 1984). For example, Liou et al. (2008) used IWC to determine the mean effective crystal size, which was then used for radiative transfer calculations. In this case, IWC was calculated based on an assumed ice crystal density, in situ measurements of the ice crystal size distribution, and the measured volumes of individual ice crystals. Though the authors take into account the differences between tropical, midlatitude, and arctic regions in terms of cloud formation processes, the datasets used for their parameterization come from only a few experiments, and measured variability of IWC is not considered.

A number of published studies present parameterizations of IWC as a function of temperature, but most have had relatively little data at their disposal to create these relationships (McFarquhar and Heymsfield, 1997; Mace et al., 2001). Although they have described the general behavior of IWC with respect to temperature, these studies have concluded that the variability of IWC measurements is difficult to parameterize on the basis of temperature alone. Heymsfield and Donner (1990) parameterized IWC as a function of large-scale meteorological variables that could be used in climate models for evaluating optical cloud properties. By including vertical velocity, they added a focus on the conditions necessary for cloud formation to their parameterization. Their results showed that while each IWC-temperature relationship at a given vertical velocity represented the in situ data well, the use of multiple expressions for a range of vertical velocities provided a more complete picture of the variability of IWC with temperature. However, the addition of more variables into a parameterization makes its implementation more complex.
In the following sections, the new, extended IWC dataset is introduced. First, the instrumentation and data processing methods are discussed (Sect. 2.1). Also, a comparison between the airborne in situ data and IWC derived from extinction measurements from a ground-based lidar is shown to demonstrate the consistency of the lowest IWC values obtained with the in situ measurements (Sect. 2.2). Next, the comprehensive nature of the merged datasets is established and the differences between the original and merged climatologies are described (Sect. 3.1). From the merged dataset, it is possible to perform a more detailed statistical analysis of IWC than that provided by Schiller et al. (2008). In Sect. 3.2, we explore the analysis of IWC solely as a function of temperature, based on probability distribution functions, an analysis method that captures the measured variability of IWC. This exploration is further expanded with the inclusion of ice particle number observations, which may offer some explanation for the distribution of IWC in a given temperature range.

\section{Instruments and analysis methods}

The in situ IWC climatology obtained from aircraft presented in this study is the result of merging two large datasets, one provided by the University of Colorado Boulder and one from the Forschungszentrum Jülich, Germany. In situ data from 13 flight campaigns, comprising 67 flights and totaling approximately $38 \mathrm{~h}$ of cirrus observations, and from two different total water instruments are included (see Table 1). In addition, observations of 142 cirrus clouds obtained with a ground-based lidar system placed in Jülich, Western Germany are compared to the in situ observations.

\subsection{FISH and CLH instruments}

\subsubsection{CLH instrument}

Four of the thirteen campaign datasets are the result of measurements by the University of Colorado closed-path laser hygrometer (CLH), which was situated aboard the NASA WB-57F aircraft or the NCAR Gulfstream G-V aircraft, depending on the campaign. The instrument works by measuring the total water amount, which is the gas phase water plus the water vapor that results from evaporating cloud particles. A heated inlet and flow path are used for sampling. Water vapor is detected by second harmonic (2f) infrared spectroscopy for smaller mixing ratios and by direct absorption for larger mixing ratios. The instrument has the ability to measure water vapor quantities ranging from about $50 \mathrm{ppmv}$ to more than $20000 \mathrm{ppmv}$.

One of the key features of this instrument is that it is coupled to a subisokinetic inlet. The inlet is forward-facing and is situated on the right-wing pod of the WB-57F aircraft with the CLH mounted behind it or on the top fuselage of the G$\mathrm{V}$, with the CLH in a rack inside the cabin. The purpose of 
Table 1. Description of the flight campaigns used to develop the IWC dataset.

\begin{tabular}{cllcccc}
\hline Instrument & Campaign & Date & \# of flights & Time in cloud (h) & Temperature Range (K) & Latitude Range \\
\hline \multirow{2}{*}{ CLH } & CRYSTAL-FACE & Jul 2002 & 11 & 9.74 & $195-229$ & $14^{\circ} \mathrm{N}-27^{\circ} \mathrm{N}$ \\
& MidCiX & Apr-May 2004 & 9 & 11.31 & $205-247$ & $26^{\circ} \mathrm{N}-38^{\circ} \mathrm{N}$ \\
& START-08 & Apr-Jun 2008 & 13 & 1.32 & $203-273$ & $33^{\circ} \mathrm{N}-53^{\circ} \mathrm{N}$ \\
& TC4 & Aug 2008 & 5 & 6.01 & $192-229$ & $1^{\circ} \mathrm{N}-37^{\circ} \mathrm{N}$ \\
\hline \multirow{2}{*}{ FISH } & APE-THESEO & Feb-Mar 1999 & 1 & 0.28 & $182-191$ & $4^{\circ} \mathrm{S}-0^{\circ}$ \\
& Cirrus 2003 & Dec & 2 & 1.20 & $203-242$ & $53^{\circ} \mathrm{N}-63^{\circ} \mathrm{N}$ \\
& Cirrus 2004 & Nov & 2 & 1.58 & $205-246$ & $55^{\circ} \mathrm{N}-64^{\circ} \mathrm{N}$ \\
& Cirrus 2006 & Nov & 4 & 1.63 & $210-235$ & $47^{\circ} \mathrm{N}-66^{\circ} \mathrm{N}$ \\
& Envisat 2002 & Oct & 1 & 0.04 & $211-232$ & $44^{\circ} \mathrm{N}-45^{\circ} \mathrm{N}$ \\
& Envisat 2003 & Mar & 2 & 0.05 & $198-205$ & $61^{\circ} \mathrm{N}-66^{\circ} \mathrm{N}$ \\
& Euplex 2003 & Jan-Feb & 2 & 0.09 & $206-236$ & $67^{\circ} \mathrm{N}-68^{\circ} \mathrm{N}$ \\
& Scout 2005 & Nov-Dec & 11 & 4.17 & $182-247$ & $15^{\circ} \mathrm{S}-18^{\circ} \mathrm{N}$ \\
& Troccinox 2005 & Jan-Feb & 4 & 0.95 & $182-224$ & $22^{\circ} \mathrm{S}-12^{\circ} \mathrm{S}$ \\
\hline \multirow{2}{*}{ Total } & 13 campaigns & & 67 & 38.38 & $22^{\circ} \mathrm{S}-68^{\circ} \mathrm{N}$ \\
\hline
\end{tabular}

CLH: Closed-path Laser Hygrometer; FISH: Fast In Situ Stratospheric Hygrometer; for details of FISH and the corresponding field campaigns see Schiller et al. (2008). The temperature and latitude ranges and the time spent in cloud are in reference to all in-cloud measurements.

the inlet is to enhance the small ice particle concentrations over the ambient amounts, which occurs because the particles cannot follow streamlines around the inlet (Davis et al., 2007a; Hallar et al., 2004; Krämer and Afchine, 2004). The evaporated cloud particle quantity is, therefore, enhanced by a known factor and is a value called enhanced IWC (eIWC). Since the CLH also measures the gas phase water in addition to eIWC, an enhanced total water $\left(\mathrm{H}_{2} \mathrm{O}_{\text {enh }}\right)$ measurement is the final output of the CLH. This has an uncertainty of $10 \%$ (Davis et al., 2007a). A detailed description of the CLH instrument, its calibration, and data analysis procedures can be found in Davis et al. (2007a). Further discussion on this topic as well as a brief description of how $\mathrm{H}_{2} \mathrm{O}_{\text {enh }}$ is converted to IWC is contained in Sect. 2.1.3.

The CLH was used in the 2002 CRYSTAL-FACE (Jensen et al., 2004), the 2004 Midlatitude Cirrus Experiment (MidCiX), the 2006 Tropical Composition, Cloud, and Climate Coupling mission (TC4, Toon et al., 2010), and the 2008 Stratosphere-Troposphere Analyses of Regional Transport (START08) campaign (Pan et al., 2010). The IWC measurements from these campaigns were taken primarily in the midlatitudes and the northern tropics.

\subsubsection{FISH instrument}

Data from the remaining nine campaigns were obtained by using the Fast In Situ Stratospheric Hygrometer (FISH), which spent time aboard the Russian high-altitude M55 Geophysica aircraft and the GFD Lear Jet throughout various campaigns. FISH is a closed-cell Lyman- $\alpha$ hygrometer that is situated inside the research aircraft with a forward-facing inlet. Similar to the CLH, FISH measures enhanced total water, but in the range of 1-1000 ppmv and with an uncertainty of $6 \% \pm 0.2$ ppmv. Additional information concerning FISH is provided by Schiller et al. (2008).

The campaigns in which FISH was utilized cover the tropics, higher midlatitudes, and the polar latitudes. The tropical measurements come from the Airborne Platform for Earth Observation's Third European Stratospheric Experiment on Ozone in 1999 (APE-THESEO, Stefanutti et al., 2004), the 2005 Stratospheric-Climate Links with Emphasis on the UTLS campaign (SCOUT-O3, Vaughan et al., 2008), and the 2005 Tropical Convection, Cirrus, and Nitrogen Oxides Experiment (TROCCINOX). The midlatitude data used by Schiller et al. (2008) and in this study are a result of the 2003, 2004, and 2006 CIRRUS experiments and the 2002 ENVISAT validation experiment. The field campaigns that yielded the arctic measurements for the climatology were the 2003 ENVISAT validation experiment and the 2003 European Polar Stratospheric Cloud and Lee Wave Experiment (EUPLEX). It should be noted that the FISH data that was included in this analysis is a subset of that from Schiller et al. (2008), coming from the 29 flights where water vapor $\left(\mathrm{H}_{2} \mathrm{O}_{\text {gas }}\right)$ was measured separately and could be used to calculate IWC from the enhanced total water $\left(\mathrm{H}_{2} \mathrm{O}_{\text {enh }}\right)$ measurement. The full Schiller climatology contains data in which IWC was determined by the difference between the total water measurement made by FISH and the water vapor saturation mixing ratio (see Schiller et al., 2008, for additional information).

\subsubsection{FISH and CLH analysis methods}

One of the first steps in the analysis was to calculate the IWC from the $\mathrm{H}_{2} \mathrm{O}_{\text {enh }}$ directly measured by the instruments. This calculation requires ambient water vapor measurements and was carried out according to the methods described in Davis 
et al. (2007a). In the case of the CLH instrument, water vapor measurements were made by the Jet Propulsion Laboratory (JPL) tunable diode laser (TDL) hygrometer (JLH), which was flown in tandem with the CLH during the flight campaigns. Data from the FISH instrument had been processed previously to obtain an IWC measurement, the details of which may be found in Schiller et al. (2008). The water vapor measurements for their calculations were made by the Lyman- $\alpha$ Stratospheric Hygrometer (FLASH) of the Central Aerological Observatory and the open-path tunable diode laser spectrometer (OJSTER) of Forschungszentrum Jülich.

A critical piece of this analysis was the development of a method that could be used to determine whether the aircraft was in or out of clouds and thus, where the data is representative of cirrus versus clear air. Based on the methods described in Krämer et al. (2009) and Schiller et al. (2008) for the FISH, FLASH, and OJSTER instruments, this can be accomplished for the CLH data using the water vapor measurements from the JLH. It should be noted that these methods have been previously applied to the datasets from the FISH instrument, so they were incorporated without further processing.

The first step is to perform a data quality check on the water vapor measurements. This is done by comparing $\mathrm{H}_{2} \mathrm{O}_{\text {gas }}$ and $\mathrm{H}_{2} \mathrm{O}_{\text {enh }}$ to one another. During periods of the experiment spent in clear air, the two measurements should agree within their respective uncertainties. During periods of the flight spent in cloud, $\mathrm{H}_{2} \mathrm{O}_{\text {enh }}$ should be greater than $\mathrm{H}_{2} \mathrm{O}_{\text {gas }}$. Flights with good fidelity to those rules are used for the analysis while flights that do not pass the test are left out. Before they are removed, however, an attempt is made to adjust the value of $\mathrm{H}_{2} \mathrm{O}_{\text {enh }}$ to ensure that $\mathrm{H}_{2} \mathrm{O}_{\text {enh }}$ and $\mathrm{H}_{2} \mathrm{O}_{\text {gas }}$ match in cases where the IWC is equal to zero. This is a reasonable procedure because the $\mathrm{CLH}$ has a higher detection limit than the JLH as a result of its short path length. When the ambient water vapor is 5 ppmv, for example, the CLH will report an $\mathrm{H}_{2} \mathrm{O}_{\text {enh }}$ measurement that is at least 20 ppmv. Davis et al. (2007b) discuss this in more detail. In the case of the CLH data, the $\mathrm{H}_{2} \mathrm{O}_{\text {enh }}$ value was adjusted with respect to the $\mathrm{H}_{2} \mathrm{O}_{\text {gas }}$ value. This was done by first calculating an adjusted water vapor measurement $\left(\mathrm{H}_{2} \mathrm{O}_{\text {gas, adj }}\right)$ using the expression

$\mathrm{H}_{2} \mathrm{O}_{\text {gas, adj }}=\mathrm{H}_{2} \mathrm{O}_{\text {enh }}-$ eIWC

Remembering that eIWC is the value calculated by subtracting $\mathrm{H}_{2} \mathrm{O}_{\text {gas }}$ from $\mathrm{H}_{2} \mathrm{O}_{\text {enh }}$ without removing the enhancement factor, Eq. (1) comes from a simple rearrangement of that relationship. Since $\mathrm{H}_{2} \mathrm{O}_{\text {gas }}$ is a measured value and $\mathrm{H}_{2} \mathrm{O}_{\text {gas }}$,adj is a value calculated from the enhanced CLH measurement, they will not likely be equal, particularly in cases of low ambient water vapor due to the limitations of the CLH as previously mentioned. What this calculation does is adjust the value of $\mathrm{H}_{2} \mathrm{O}_{\text {gas }}$ relative to $\mathrm{H}_{2} \mathrm{O}_{\text {enh }}$ so that it passes the data quality check. However, the value of $\mathrm{H}_{2} \mathrm{O}_{\text {gas, adj }}$ is not physically meaningful since the adjusted water vapor measure-

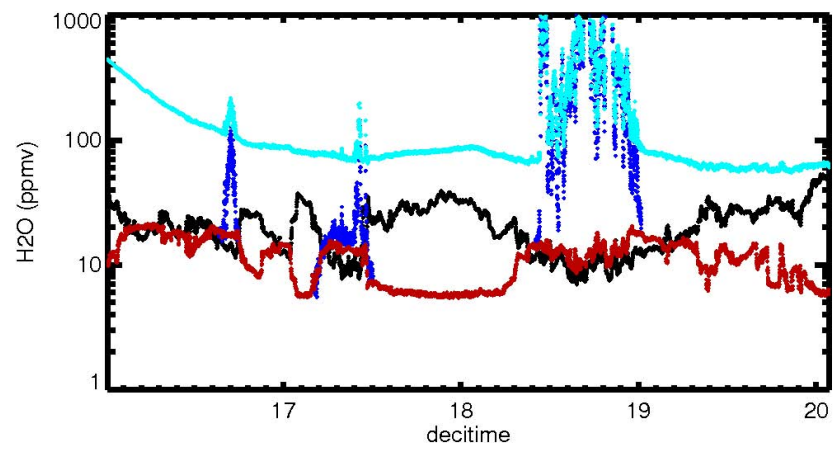

Fig. 1. This figure illustrates the $\mathrm{H}_{2} \mathrm{O}$ data quality check using data obtained by the CLH during the CRYSTAL-FACE campaign on 9 July 2002. The black line is $\mathrm{H}_{2} \mathrm{Osat}$, the red line is $\mathrm{H}_{2} \mathrm{O}_{\text {gas }}$, the turquoise line is $\mathrm{H}_{2} \mathrm{O}_{\text {enh }}$, and the dark blue line is $\mathrm{H}_{2} \mathrm{O}_{\text {enh, adj. }}$.

ment will always be greater than the saturation water vapor mixing ratio, indicating that the aircraft was always inside cloud. To correct for this, the original enhanced total water measurement, $\mathrm{H}_{2} \mathrm{O}_{\text {enh }}$ is adjusted relative to $\mathrm{H}_{2} \mathrm{O}_{\text {gas }}$, thus creating $\mathrm{H}_{2} \mathrm{O}_{\text {enh, adj, which is defined here as }}$

$\mathrm{H}_{2} \mathrm{O}_{\text {enh, adj }}=\mathrm{H}_{2} \mathrm{O}_{\text {enh }}-\left(\mathrm{H}_{2} \mathrm{O}_{\text {gas, adj }}-\mathrm{H}_{2} \mathrm{O}_{\text {gas }}\right)$

The difference between the adjusted water vapor and the measured water vapor should be the same value as the difference between the adjusted and measured enhanced total water, thus it can be used in the above calculation. Now, $\mathrm{H}_{2} \mathrm{O}_{\text {enh, adj }}$ and $\mathrm{H}_{2} \mathrm{O}_{\text {gas }}$ are both physically meaningful values that can potentially pass the data quality check. There is still the chance that the adjustment will yield results with a large scatter between the adjusted and measured values indicating a poor agreement on the characteristics of the measurement between the CLH and JLH, and in that case, the data are taken out of the analysis. An example graphical representation of these values and the adjustment can be seen in Fig. 1 where $\mathrm{H}_{2} \mathrm{O}_{\text {gas }}$ (red), $\mathrm{H}_{2} \mathrm{O}_{\text {enh }}$ (turquoise),

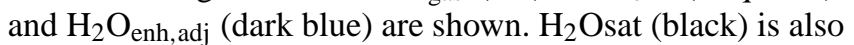
shown to illustrate that $\mathrm{H}_{2} \mathrm{Ogas}$ and $\mathrm{H}_{2} \mathrm{O}_{\text {enh, adj }}$ are physically meaningful values.

After completing the data quality check, the water vapor data are usable for calculating the relative humidity with respect to ice $\left(\mathrm{RH}_{\text {ice }}\right)$ and the enhanced relative humidity with respect to ice $\left(\mathrm{eRH}_{\mathrm{ice}}\right)$, which together is the basis for the method used to determine whether a particular data point was measured "in-cloud" or in clear air. The parameter $\mathrm{RH}_{\text {ice }}$ was chosen to distinguish between clouds and clear air because it is more sensitive to changes than water vapor (Krämer et al., 2009). e $\mathrm{RH}_{\text {ice }}$ is calculated from the $\mathrm{H}_{2} \mathrm{O}_{\text {enh }}$ measurement while $\mathrm{RH}_{\text {ice }}$ is calculated from $\mathrm{H}_{2} \mathrm{O}_{\text {gas }}$. The ratio of $\mathrm{eRH}_{\text {ice }}$ to $\mathrm{RH}_{\text {ice }}$, called a cloud limit, is the parameter that defines where a cloud exists and is instrument specific. When $\mathrm{eRH}_{\text {ice }} / \mathrm{RH}_{\text {ice }}$ is greater than 1 , and $\mathrm{eRH}_{\text {ice }}$ is greater than $100 \%$, saturated or supersaturated cirrus is being sampled. 
However, due to measurement uncertainties and data scatter, when the ratio is barely greater than 1 , it is difficult to determine if the sample is in cloud or not (Krämer et al., 2009). Thus, a cloud limit value that is greater than, but not equal to, 1 must be employed. A second, higher cloud limit is also needed for cases where the $\mathrm{eRH}_{\text {ice }}$ values are less than $100 \%$, which could indicate subsaturated cirrus. For example, in Krämer et al. (2009), the cloud limits used are 1.03 and 1.3. When those specific values are applied to the IWC data from the CLH instrument, IWC measurements smaller than the detection limits of the instrument remain included in the dataset as measurements from inside a cloud. Since those measurements cannot be confidently determined to be in cloud, they should not be included in the dataset. In order to remove those values, higher cloud limits were put in place. In the case of the CLH data, the cloud limits were determined to be 1.3 and 3 .

There are three possible scenarios for each data point, which are as follows. The first is a scenario indicating that the data point definitely represents a measurement taken inside a cirrus cloud. In this scenario, $\mathrm{RH}_{\text {ice }}$ and $\mathrm{eRH}_{\text {ice }}$ are both greater than $100 \%$ and $\mathrm{eRH}_{\text {ice }} / \mathrm{RH}_{\text {ice }}$ is greater than 1.3. In the second scenario, $\mathrm{eRH}_{\text {ice }}$ is greater than $100 \%$ but $\mathrm{RH}_{\text {ice }}$ is not. As long as $e \mathrm{RH}_{\text {ice }} / \mathrm{RH}_{\text {ice }}$ is greater than 1.3, the data point is most likely in cloud. The last scenario is for data points where neither $\mathrm{RH}_{\text {ice }}$ nor $\mathrm{RH}_{\text {ice }}$ is greater than $100 \%$. For this case, the larger cloud limit is used to ensure that if a data point is to be included and labeled "in-cloud", it is definitely a cirrus measurement. Thus, in order for it to be included, $\mathrm{eRH}_{\mathrm{ice}} / \mathrm{RH}_{\mathrm{ice}}$ must be greater than 3. Data that do not fall into one of these three categories are assumed to be measurements made in clear air and are not included in the climatology.

Another screening method that was applied to the data is the determination of geographic location for the datasets. It is understood that cirrus properties vary from region to region due to the differences in atmospheric conditions that exist between them (McFarquhar and Heymsfield, 1997). Similar to Schiller et al. (2008), the divisions between regions were made based on familiar latitudinal definitions. The tropics were defined to be between the Tropics of Cancer and Capricorn at $23.5^{\circ} \mathrm{N}$ and $23.5^{\circ} \mathrm{S}$, respectively; the midlatitudes are between $23.5^{\circ}$ and $60^{\circ}$ in either hemisphere; and the polar region was considered to be latitudes greater than $60^{\circ}$ in either hemisphere. In general, these definitions work well. However, in the case of the START-08 dataset, there was cause for some uncertainty, because this campaign began in the late spring and ended in the early summer, a time during which atmospheric conditions change because of the increasing height of the tropopause with the heating of the atmosphere. Since the tropical region is partly defined by a high tropopause, a shift in the latitudes where the tropopause is highest makes using a rigid latitudinal definition of geographic regions questionable. To accommodate this, a different scheme was developed to use the polar and subtropical jet streams as boundaries between the arctic and the midlatitudes, and between the midlatitudes and tropics, respectively. Since the jet streams change locations depending on the season, they were ideal for this analysis. The geographic region for each dataset from the START-08 campaign was determined using upper-level weather maps, which revealed the positions of the jet streams for that day. The data were then labeled and separated accordingly. For data points falling in the midst of a jet stream, the assumption is made that those points display the characteristics of both geographic regions and they are thus displayed as part of both.

\subsection{Comparison of Leo-Lidar with FISH-CLH}

Lidar (Light Detection and Ranging) is an active remotesensing instrument measuring the optical properties of atmospheric particles. The backscatter and extinction coefficients as well as the depolarization of a particle ensemble (e.g., cirrus ice particles) can be determined from the backscattered light. The lidar used here is a commercial mobile backscatter lidar system (Leosphere), named Leo-Lidar, that works at a wavelength of $355 \mathrm{~nm}$ with a repetition rate of $20 \mathrm{~Hz}$. The extinction coefficient as well as the IWC depends upon the particle size distribution of an ice particle ensemble, which allows the determination of IWC from extinction measurements. Thus, IWC and extinction $(\sigma)$ are approximately proportional to each other. Here, the IWC of cirrus clouds is determined by using the relation provided by Heymsfield et al. (2005)

$\operatorname{IWC}\left(\mathrm{g} \mathrm{m}^{-3}\right)=a \cdot \sigma\left(\mathrm{m}^{-1}\right)^{b}$

which is derived from extinction and IWC measurements from aircraft in situ sensors compared with data from the spaceborne instruments CloudSat radar and Calipso Lidar. The parameters $a$ and $b$ are given by 89 $+0.6204 \cdot T\left({ }^{\circ} \mathrm{C}\right) \mathrm{g} \mathrm{m}^{-2}$ and $1.02-0.00281 \cdot T\left({ }^{\circ} \mathrm{C}\right)$, respectively.

The extinction $(\sigma)$ of a cirrus cloud and thus IWC is determined as follows. First, the Leo-Lidar measurements are averaged in time over the whole observed cirrus cloud with a vertical resolution of $60 \mathrm{~m}$. This gives a cloud profile with a high signal-to-noise ratio to be used in further analysis. To determine the extinction profile, a fixed lidar ratio has to be assumed. This ratio is usually constant for one ice particle composition, shape, and particle size distribution within a cirrus layer. Under the assumption of a particle-free atmosphere directly below and above the cirrus cloud, the lidar ratio is estimated as described by Seifert et al. (2007). In the vicinity of clouds this assumption is valid for wavelengths $\lambda \leq 532 \mathrm{~nm}$ as reported in Ansmann (2002). A multiple scattering correction is also applied to the cirrus extinction profile. The particle size-dependent multiple scattering occurs when the forward scattered laser light is scattered again by an ice particle, which leads to an underestimation of the extinction coefficient (for more details see Rolf et al., 2012). 


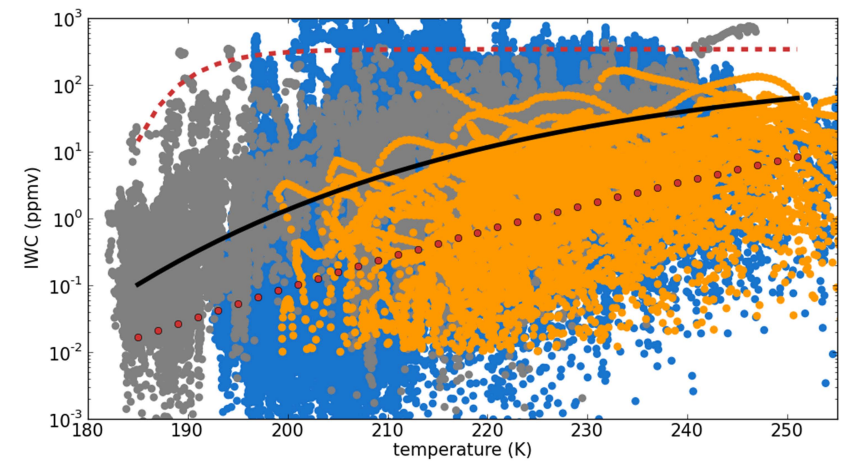

Fig. 2. IWC as a function of temperature for CLH (blue), FISH (grey) and Leo-Lidar (orange). The red dotted lines represent the IWC maximum and the minimum that can be detected with certainty by CLH and FISH (Schiller et al., 2008; Krämer et al., 2009), respectively. The back solid line is the median of the merged CLH and FISH dataset.

The Leo-Lidar measures IWC in the range $0.01-400 \mathrm{ppmv}$ with a mean uncertainty of $12 \%$. Thus, the upper detection limit is below those of CLH and FISH, but the lower detection limit is below the minimum IWC that can be detected with certainty by CLH and FISH (Schiller et al., 2008; see red dotted line in Fig. 2). For lower IWC from CLH and FISH it is uncertain if the signal stems from instrument uncertainties or from a cloud (see Krämer et al., 2009, their in-cloud definition is applied to the IWC measurements). Thus, the inclusion of Leo-Lidar cirrus observations provides the opportunity to compare the small IWC values from CLH and FISH with these measurements.

During the period of Spring 2011 to Spring 2012, 142 ground-based cirrus observations were performed with the Leo-Lidar over mid-latitude Jülich, western Germany $\left(50^{\circ} 54^{\prime} \mathrm{N}, 6^{\circ} 24^{\prime} \mathrm{E}\right)$. In Fig. 2 the complete CLH and FISH IWC datasets are shown as a function of temperature in blue and grey, respectively. The Leo-Lidar measurements are plotted in orange. The upper IWC detection limit of the LeoLidar is clearly visible. The lower Leo-Lidar IWC values coincide nicely with those of the in situ dataset for temperatures $>230 \mathrm{~K}$. Most notable is the agreement of the data below the red dotted line, the minimum IWC that can be detected with certainty by CLH and FISH. At temperatures below $230 \mathrm{~K}$, CLH and FISH measured IWCs even smaller than those detectable by the Leo-Lidar, but that is with low certainty.

The Leo-Lidar IWC dataset is not merged with that of CLH and FISH for the remaining analyses presented here since high IWC values are not included in the Leo-Lidar observations, thin cirrus are missed in the temperature range 200-230 K and no measurements exist below $200 \mathrm{~K}$. However, from the comparison of the lidar and in situ IWC climatologies there is strong indication that the low IWC data measured with the in situ instruments are cirrus clouds and not artificial instrument effects. Moreover, it seems that the

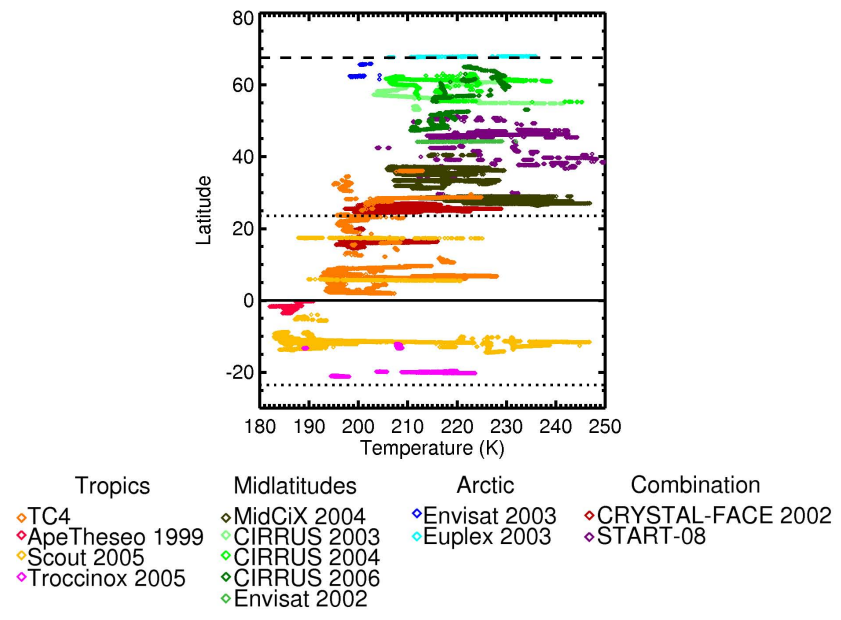

Fig. 3. The latitudinal coverage achieved by the combined dataset. The color scheme in the legend is used consistently throughout the rest of the analysis.
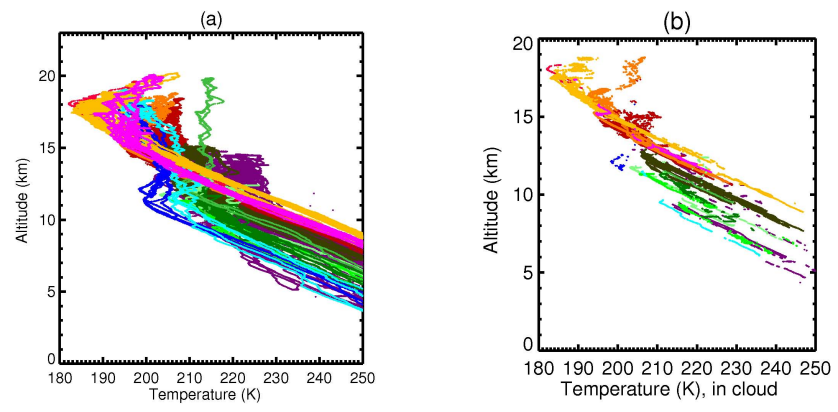

Fig. 4. (a) Temperature and altitude coverage of all data taken during all campaigns. (b) Same as (a) but for in-cloud data only. The color scheme is the same as in Fig. 3.

in situ instruments do not miss very thin cirrus clouds but cover the whole atmospheric cirrus IWC range.

\section{Results and discussion}

\subsection{Extended cirrus dataset}

One major result of this study is the merging of two large datasets, which yields an even larger and more comprehensive picture of cirrus IWC than that published by Schiller et al. (2008) and one that is representative of nearly all latitudes. The latitudinal coverage of the data is illustrated by Fig. 3; combining the US and European datasets minimized the gaps in latitudinal sampling. For example, the MidCiX, CRYSTAL-FACE, and START-08 data filled a hole in the Schiller data between 0 and $40^{\circ} \mathrm{N}$. In terms of longitudinal coverage, it should be noted that the data comes from field campaigns that focused largely on the Western Hemisphere.

To further demonstrate the comprehensive nature of the dataset, Fig. 4 shows the range of altitudes and temperatures 


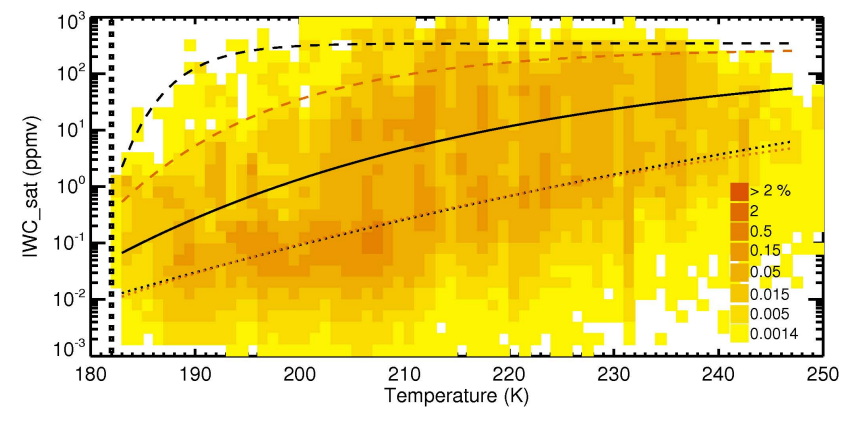

Fig. 5. IWC as a function of temperature. Color scheme is the frequency of data points with respect to the total number of sampled data. The overall data base represents $38.4 \mathrm{~h}$ (138240 data points) of in-cloud sampling as noted in Table 1. Black solid/dashed dotted lines are median/maximum/minimum IWC, red dashed/dotted lines encompasses the core IWC region of the climatology of Schiller et al. (2008).

that are covered. Although the Arctic data are sparser than that in the other regions, in general, observations were obtained throughout the mid- and upper troposphere and even slightly above the tropopause. Thus, the temperatures and altitudes at which cirrus occur are well represented.

The CLH and FISH datasets complement each other as a result of differences in instrument capabilities. For example, the lower limit of the FISH instrument allows for accurate measurements in very thin cloud not accessible by the CLH. On the other hand, the CLH has the ability to measure water vapor mixing ratios that are too large for the FISH to measure. In this regard, the two datasets are able to offer the full range of atmospheric IWC values, but only when used together.

Altogether, the dataset used in this analysis encompasses the latitude range from $22^{\circ} \mathrm{S}$ to $68^{\circ} \mathrm{N}$, the altitude range from 5 to $20 \mathrm{~km}$ and the temperature range $182-249 \mathrm{~K}$. It represents $38.2 \mathrm{~h}(27500 \mathrm{~km})$ of cloud sampling (137409 data points; for more details of the 13 field campaigns between 1999 and 2008 see Table 1).

The statistical significance of the dataset is demonstrated in Fig. 5, where all observed IWCs are shown as a function of temperature. The color scheme is the frequency of data points with respect to the total number of sampled data. It can be seen that the complete large temperature and IWC range of cirrus is covered by the measurements (it should be noted, however, that the TTL cirrus at temperatures $<200 \mathrm{~K}$ were probed with a little lesser frequency than the other temperatures due to the fact that fewer field campaigns took place in the tropics). The dataset includes samples collected only one second apart, which might not be regarded as independent from each other. However, we believe that the reliability and statistical significance of the dataset is given by the spread of IWCs over several orders of magnitude sampled in each temperature interval.
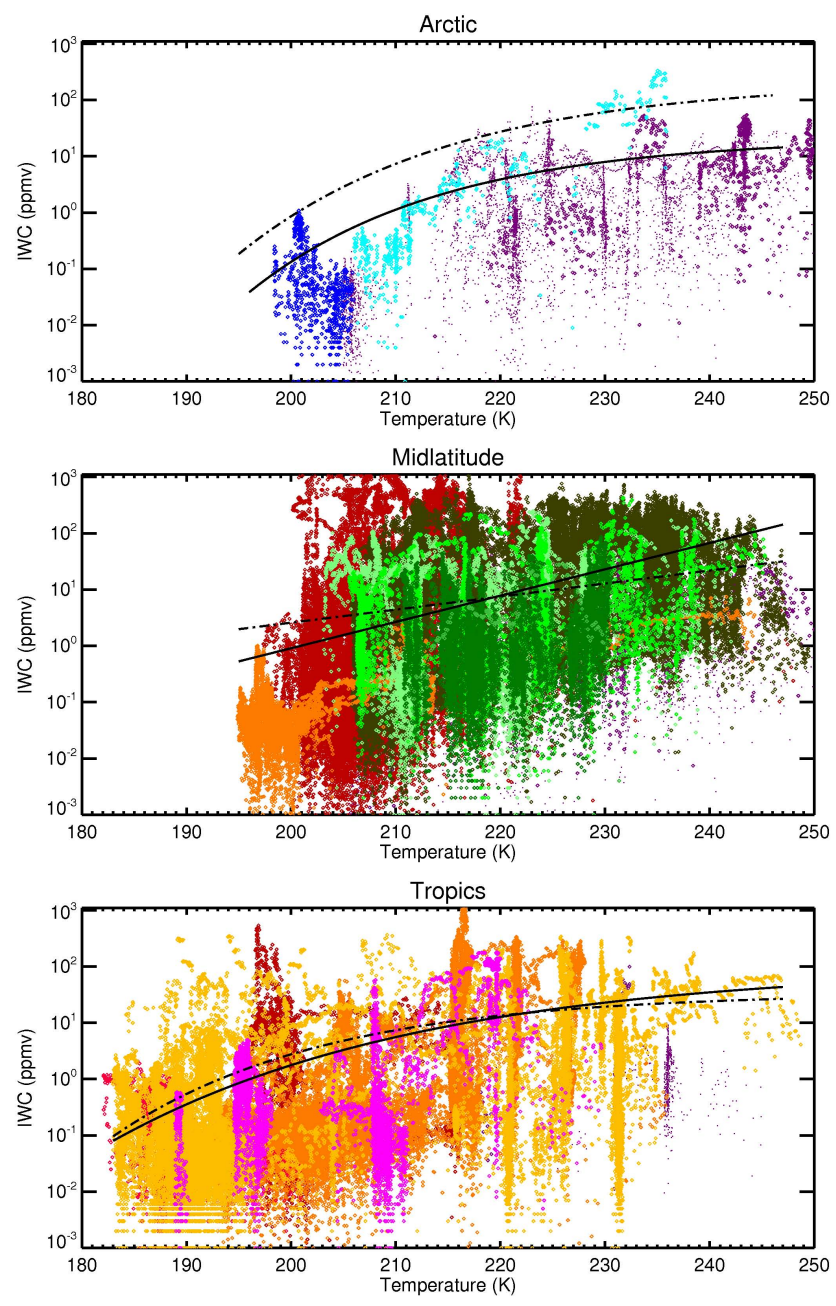

Fig. 6. IWC as a function of temperature and geographic region. Color scheme as in Fig. 3. Data points represented as small dots are a combination of geographic locations and thus included in two plots (see text). The black line represents the median fit, while the dashed black line is the median fit from Schiller et al. (2008). It should be noted that the median fit lines from the Schiller climatology include convective data.

From Fig. 5 it can also be seen that, as expected, IWC increases with temperature, a general relationship that is already well documented (see Fig. 5 of Schiller et al., 2008). This behavior is seen again in Fig. 6, which lends confidence to the use of the CLH and FISH datasets in combination. Another feature that is also obvious in Fig. 6 is the broad range of IWC values for a given temperature, showing that the temperature-IWC relationship is complicated and requires the use of additional variables (e.g., vertical velocity, geography, etc.) to explain it.

One variable that is known to play a role in the temperature-IWC relationship is geographic region. Thus, the dataset was divided by geographic region: arctic, midlatitude, or tropics. Figure 6 shows how the temperature-IWC 
relationship changes as a function of geographic region. By comparing the three plots, it is easily observed that for each region, the relationship has a unique shape. Median fit lines have been developed to more clearly define the relationships. The fit lines are a function of the form $10^{\left(a b^{T}+c\right)}$ as in Schiller et al. (2008). For this paper, the fit lines were developed using data that came only from flights where the purpose was to sample cirrus other than that associated with active tropical deep convection. The flights focused on convection include the SCOUT-O3 flights on 23, 29, and 30 November 2005, the START-08 flight on 16 June 2008, and the TC4 flights on 5, 6 , 8 , and 9 August 2007. Cirrus formed in association with tropical deep convection have been shown to have very high IWC values at very low temperatures (Schiller et al., 2008) so data from these flights have been removed from the development of any fit lines in this analysis. Using those data in the analysis has the potential to yield results that inaccurately depict the relationship between temperature and IWC. It should be noted, however, that all data, convective and nonconvective, are shown in Fig. 6, as well as in the previous figures.

It can be clearly seen that new fit lines developed for the merged dataset compare well to those developed from the FISH observations by Schiller et al. (2008). For the tropical data, the new median fit line is very close to the old one, with the obvious differences occurring at the lower and higher temperatures where smaller and larger IWC values, respectively, are now more evenly represented. In the case of the midlatitudes, the difference between the new and old median fit lines is more significant. Once again, smaller IWC values are now influencing the median fit line more heavily in the lower temperature ranges, while the larger IWC values are doing the same at the higher temperature ranges. The new median fit line for the arctic data appears to have changed the most from the median fit line used by Schiller et al. (2008). For all temperatures the new median fit line is located at a smaller IWC, but the overall shape of the fit line has been preserved. This is most likely due to the differences in arctic datasets used for this analysis versus the data that were used by Schiller et al. since only a subset of those data is used in this analysis.

For all regions, the alterations in the fit lines could be a result of seasonal differences between the two original datasets. The observations from FISH resulted from experiments that took place in the boreal fall and winter months while the experiments that the CLH was a part of took place in the boreal spring and summer months. The possibility of a seasonal effect is not explored further in this paper.

\subsection{New statistical analysis}

\subsubsection{Ice water content}

In the introduction we noted work that has been done to parameterize IWC. Although the use of multiple variables helps to describe the range of IWC observed in nature, it does not fully capture the variability and is thus incomplete. Rather than attempting to incorporate multiple variables in this work, we describe the IWC-temperature relationship through probability density functions (PDFs). These represent the distribution of IWC values for specific temperature bins without considering the mechanism(s) responsible for the variation.

The first step in our analysis is to develop PDFs from the full, merged dataset separated into $5 \mathrm{~K}$ temperature bins (Fig. 7). The full dataset (grey and blue dots in Fig. 2) was utilized because there is not sufficient data to accurately describe the behavior in each temperature bin for each geographic region. Note that the lowest temperature bin spans 180-194 K and the highest temperature bin spans 235-249 K. These bins are wider due to the limited amount of data that was collected at those temperatures. However, it is likely that the clouds in these bins share common development mechanisms. The 180-194 K temperature range is known to have cirrus formation mechanisms that are different from those seen in warmer regions of the troposphere (Krämer et al., 2009; Jensen et al., 2010; Spichtinger and Krämer, 2012). The 235-249 K temperature range, on the other hand, probably contains mixed-phase clouds that would alter the distribution of condensed water content with respect to temperature. It should be noted that the data used to develop the PDFs do not include samples taken in active tropical deep convection for the same reasons discussed previously. While tropical deep convection is important as a mechanism for cirrus formation, the temperature-IWC relationship that results is different enough from that of other cirrus formation mechanisms that we feel it should be analyzed separately.

As expected, the IWC distribution changes from bin to bin, with smaller IWC values dominating the distribution in the lower temperature bins and the largest IWC values dominating the distribution in the higher temperature bins. This is consistent with the known IWC-temperature relationship. The shape of the distribution is similar in each temperature bin, and it is bimodal in nature, except for the $195 \mathrm{~K}-199 \mathrm{~K}$ bin, where the PDF shows several peaks. This difference is likely due to a smaller number of data points in the bin or potentially to the presence of multiple formation mechanisms exerting influence on the PDF. In general, the two peaks of the distribution shift monotonically in IWC value with temperature. As the temperature increases, the height of the first peak decreases, while the second peak shifts to larger values.

The PDF plots shown in Fig. 7 are ideal for capturing the IWC variability over small temperature ranges. Using the approximately Gaussian shape of the two modes in the PDFs, we have developed a fit function that describes IWC as a function of temperature, while also representing the variability of the IWC. It should be noted that this relationship is meant to describe the observations found in the statistical analysis of our data, not as a parameterization for use in modeling. We have used a modified Gaussian fit developed 

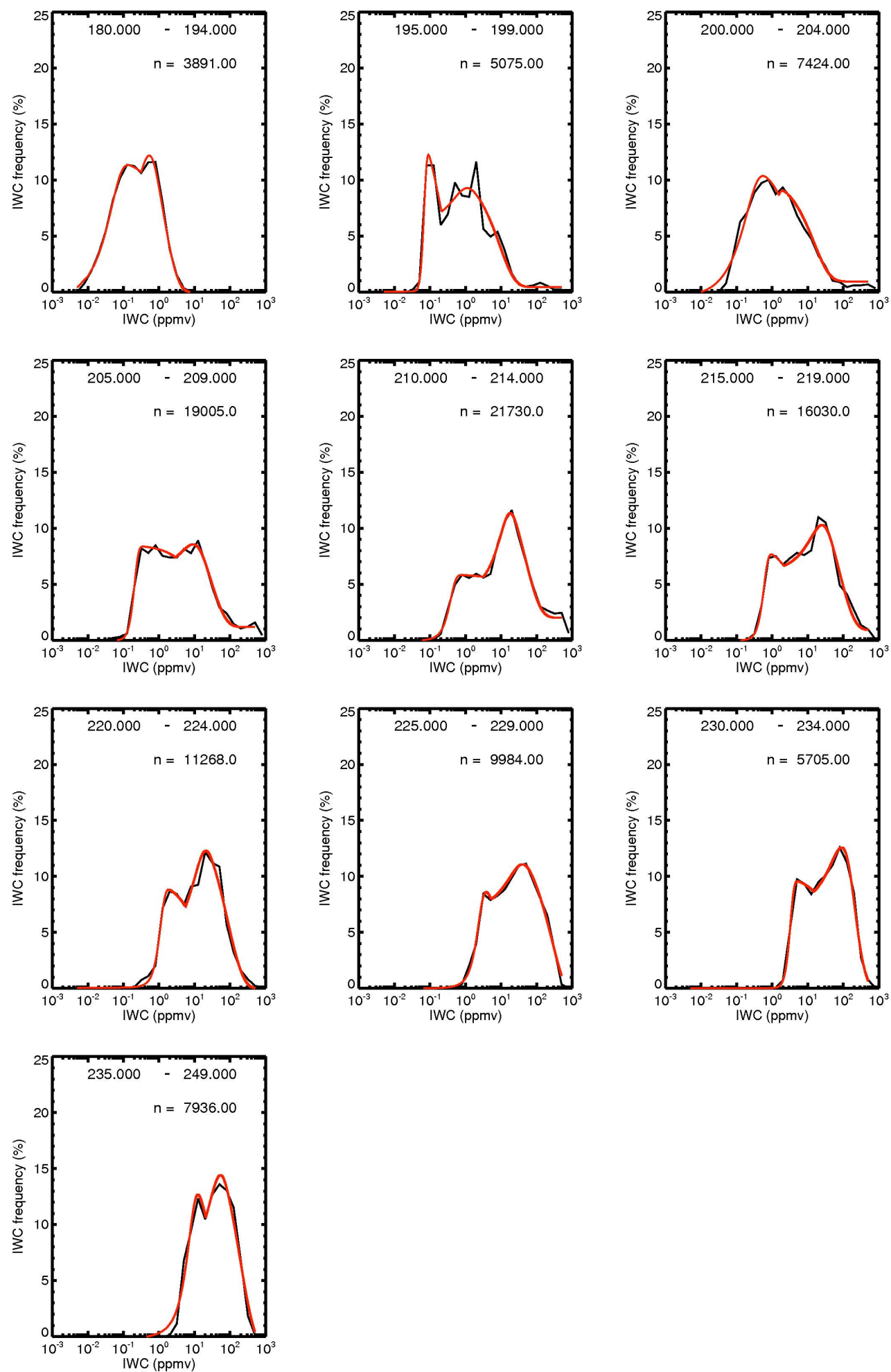

Fig. 7. PDFs of IWC in various temperature ranges. The black lines are the PDF, the red lines are the curve fits. 


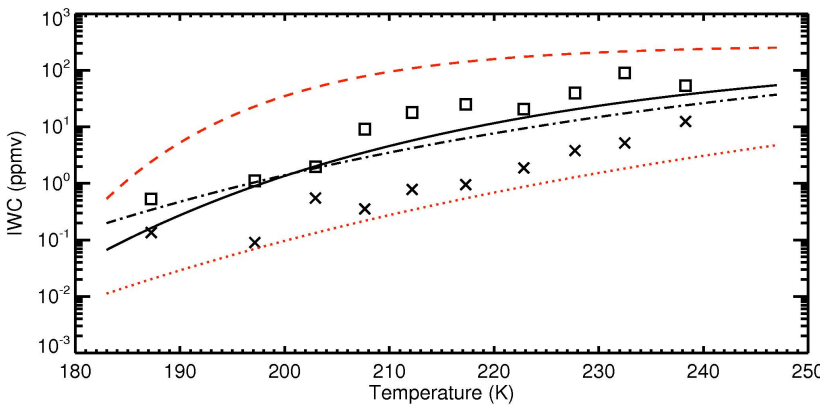

Fig. 8. Peaks of the bimodal PDFs from Fig. 7. " $X$ " is the value of the first (lower IWC) peak, a square is the value of the second. The temperature at which they are plotted is the weighted mean temperature for each temperature bin. The black line represents the median fit line for the merged climatology, not including tropical deep convective data. The black dashed line is the median fit from Schiller et al. (2008) and includes convective data. The red dashed/dotted lines depict the maximum/minimum envelope of the most frequent ( $>5 \%$ ) IWC as seen in Fig. 6 of Schiller et al. (2008).

in the data analysis software package OriginPro 8.1 (OriginLab, Northampton, MA) that was originally intended for use in chromatography. In the equation

$f(x)=y_{0}+\frac{A}{t_{0}} \exp \left[\frac{1}{2}\left(\frac{w}{t_{0}}\right)^{2}-\frac{x-x_{c}}{t_{0}}\right] \int_{-\infty}^{z} \frac{1}{\sqrt{2 \pi}} \exp \left(\frac{-y^{2}}{2}\right) \mathrm{d} y$

where $z$ is given as

$z=\frac{x-x_{c}}{w}-\frac{w}{t_{0}}$

$x$ and $f(x)$ are the IWC (ppmv) and IWC frequency (\%), respectively. The remaining coefficients $(y, t, w, A$, and $z)$ are constants fit by the OriginPro program and do not hold any physical meaning in terms of the contributing variables associated with IWC. They are purely used as descriptors of the curves fitting the PDFs. To accommodate the fact that the curves are bimodal, each PDF was treated as two Gaussian curves that overlap one another between peaks. The division between where one curve stopped and the other started was made on a case-by-case basis and was determined based on what appeared to provide the best fit. Figure 7 also illustrates the curves that were fit to each PDF. The coefficients for each curve and temperature bin can be found in the supplemental material.

An additional depiction of the relationship observed in the PDFs is provided in Fig. 8 to show its representative nature. The two most frequently observed IWC values are plotted for each temperature bin, along with median fit functions to the entire dataset as determined here and in Schiller et al. (2008). It can easily be seen that there is a defined structure to the relationship between those IWC values and temperature and that it is similar in shape to the median fit. Also, the median fit lines fall directly between the two IWC values. In Schiller
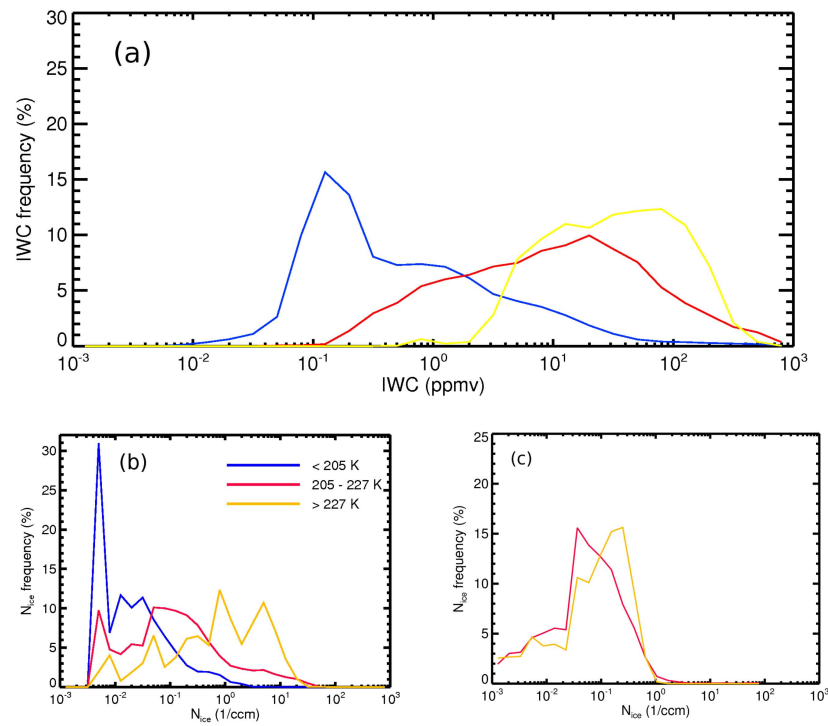

Fig. 9. (a) Top: PDF of IWC; (b) Bottom-left: PDF of crystal number (FSSP); (c) Bottom-right: PDF of crystal number (CAPS). (b) is reproduced from Fig. 7a of Salzmann et al. (2010).

et al. (2008), a core region was defined where the frequency of occurrence was greater than $5 \%$. The minimum and maximum values of that core region are illustrated in Fig. 8 by the dotted and dashed red lines, respectively. The peak IWC values for each temperature fall well within that core region, which lends confidence to the idea that these values are representative of a large portion of the data.

\subsubsection{Ice water content and crystal number}

In order to interpret the meaning of the IWC-PDFs, PDFs where the data have been divided into three temperature ranges are looked at, as seen in Fig. 9a. The ranges used here correspond to the three temperature ranges used in Fig. 7a of Salzmann et al. (2010), which is reproduced here as Fig. 9b. The PDF graphs show ice crystal numbers (Ni) observed using a Forward Scattering Spectrometer Probe (FSSP, see Krämer et al., 2009). Unlike the previous PDFs, these were constructed with all data including tropical deep convective data (but note that the PDFs excluding convective data, not shown here, are nearly identical).

Since the measurements from Krämer et al. (2009) are not corrected for artifacts produced by ice crystal shattering, possible shattering effects on the Ni-PDFs are discussed here. For that purpose, cirrus ice crystal numbers that are corrected for shattering are compared to those shown in Fig. 9b. Figure 9c shows Ni-PDFs in two temperature ranges, which come from measurements taken by the CAPS probe (Cloud and Aerosol Particle Spectrometer, Baumgardner et al., 2001) onboard the British BAE-146 during the Combined Observation of the Atmospheric boundary Layer to study the Evolution of StratoCumulus (COALESC) campaign in 2011 
over the UK. The CAPS data acquisition includes records of particle interarrival times so that a removal of artifacts from shattering is possible. In addition, shattering was reduced by improving the CAPS sampling characteristics (Meyer et al., 2013).

Inspecting the Ni-PDFs in panels $b$ and $c$ of Fig. 9 shows that in the lower temperature range (red curves) both PDFs are of a bimodal nature, though in the COALESC dataset the peak at low Ni is much weaker than in the Krämer et al. (2009) dataset. In addition, a small amount of Ni concentrations larger than $1 \mathrm{~cm}^{-3}$ are visible in this dataset, which possibly originate from crystal shattering. The same conclusion holds for the higher temperature range (yellow curves), but as expected the contribution of $\mathrm{Ni}$ concentrations larger than $1 \mathrm{~cm}^{-3}$ is higher than at colder temperatures. No measurements for $T<205 \mathrm{~K}$ were available from the COALESC observations, but it is likely that at the low temperatures shattering does not play an important role. In summary, it can be seen that the general shape of the Ni-PDFs is bimodal, and also that the peaks at larger $\mathrm{Ni}$ concentrations shift to higher values with increasing temperature.

A comparison of the IWC-PDFs with the Ni-PDFs, for each of the three temperature ranges (blue: $<205 \mathrm{~K}$, red: 205-227 K, yellow: $>227 \mathrm{~K}$ ), shows that there is a similarity in the overall shape of the distributions, suggesting a connection. For example, and most noticeably, the narrow peak in ice number at approximately $0.005 \mathrm{~cm}^{-3}$ in the very low temperature range (blue curve), which is representative of conditions found at the tropical tropopause layer (TTL), coincides with a peak in IWC at approximately $0.1 \mathrm{ppmv}$, while a second broader peak appears at higher ice crystal numbers and IWCs. It is remarkable that the bimodal nature of the cirrus PDFs is found by two completely independent measurements. As a possible explanation of this structure of the ice crystal number frequencies, Spichtinger and Krämer (2012) propose, from extensive model simulations in comparison to the TTL cirrus observations of Krämer et al. (2009), that the first peak around $0.005 \mathrm{~cm}^{-3}$ is mainly caused by heterogeneous ice nucleation, while the higher ice crystal numbers stem from homogeneously formed cirrus clouds.

The remaining two temperature ranges are more difficult to interpret. It is clear, however, that there are two modes for each temperature range, both in IWC and $\mathrm{Ni}$, thus providing us with good reason to speculate that they are linked to one another.

We summarize our findings with the following hypotheses: (i) the IWC is influenced by the ice crystal number, (ii) the IWC PDFs are observed to be bimodal over the complete cirrus temperature range, (iii) for cold TTL cirrus, it is highly likely that the mode with only a few ice crystals (low IWC) corresponds mainly to heterogeneous ice formation while the mode with a higher number of ice crystals (higher IWC) can be attributed to homogeneous ice formation. Extending the physical explanation of the two ice number/IWC modes from TTL cirrus to higher temperatures leads to the conclu- sion that both heterogeneously and homogeneously formed cirrus clouds are visible in the IWC PDFs as two modes of lower and higher IWC, where the lower and weaker Ni/IWC mode might represent heterogeneous freezing and the higher and stronger mode represents homogeneous freezing, as one would expect. This might be a hint that heterogeneous freezing plays a larger role in cirrus modification than believed hitherto (Kärcher et al., 2009).

\section{Conclusions}

The importance of cirrus in the climate system is well documented, but the details are not yet well understood. The IWC of these clouds is also known to have a crucial role in that system through its effect on terrestrial and solar radiation, but it is difficult to parameterize owing to the large variability in IWC values possible for a given set of atmospheric conditions. Here, we have presented the extension of a cirrus IWC climatology originally developed by Schiller et al. (2008). This extension provides a highly comprehensive dataset in terms of covering the temperature, altitude, and latitude ranges at which cirrus are observed and the IWC values that are known to be present in those clouds. It was also shown here through a comparison with lidar data that the reported smallest IWC values are valid cirrus measurements.

Previous work to create IWC parameterizations has been successful in exploiting the general relationship between IWC and temperature, but has been unable to capture the variability of IWC at a single temperature without the use of additional variables. Through the use of PDFs, we have been able to demonstrate and create a description of IWC in $5 \mathrm{~K}$ temperature bins that relies solely on the IWC-temperature relationship while still including the large range of IWC in a small temperature range.

The peak IWC values of the PDFs were shown to be consistent with the IWC-temperature relationship seen with the full, extended climatology and were easily bounded within a core region of the most frequent IWC values. It was also shown that the use of PDFs for describing the microphysical properties of ice clouds is both appropriate and useful. The comparison between IWC and Ni-PDFs indicate that the relationship between IWC and temperature is influenced by particle number. Further, we found hints that the general bimodal nature of the IWC PDFs might be caused by the two pathways for ice formation, namely heterogeneous and homogeneous freezing. The underlying microphysical processes that lead to a connection among Ni, IWC and the cirrus formation mechanism are the subject of a follow-up study; further discussion will appear in a separate paper.

While the relationships determined by our analysis are not appropriate for direct use in climate models, we have provided an extensive dataset that can be useful for comparison and evaluation purposes. We will continue to utilize the expanded climatology to make further inquiries into the 
mechanisms responsible for determining IWC in order to enhance our understanding and improve the parameterizations used in global climate models.

\section{Supplementary material related to this article is available online at: http://www.atmos-chem-phys.net/13/ 6447/2013/acp-13-6447-2013-supplement.zip.}

Acknowledgements. L. M. Avallone and A. E. Luebke acknowledge support for this research from NASA Earth Science Division Radiation Sciences Program and Upper Atmosphere Research Program under grants NNX07AL20G and NNX10AO27G. M. Krämer and J. Meyer are grateful to Martin Gallagher and James Dorsey from the University of Manchester, UK, as well as the UK Met Office for giving them the opportunity to operate their CAPS on the BAE-146. All of the authors would also like to thank the reviewers for their comments leading to an improved manuscript.

Edited by: D. J. Cziczo

\section{References}

Ansmann, A.: Molecular-Backscatter Lidar Profiling of the Volume-Scattering Coefficient, in: Cirrus, edited by: Lynch, D. K., Sassen, K., Starr, D. C., and O'Stephens, G., Oxford University Press, New York, NY, USA, 197-210, 2002.

Baumgardner, D., Jonsson, H., Dawson, W., O'Connor, D., and Newton, R.: The cloud aerosol and precipitation spectrometer: a new instrument for cloud investigations, Atmos. Res., 59-60, 251-264, 2001

Davis, S. M., Hallar, A. G., and Avallone, L. M.: Measurement of Total Water with a Tunable Diode Laser Hygrometer: Inlet Analysis, Calibration Procedure, and Ice Water Content Determination, J. Atmos. Ocean. Technol., 24, 463-475, doi:10.1175/JTECH1975.1, 2007a.

Davis, S. M., Avallone, L. M., Weinstock, E. M., Twohy, C. H., Smith, J. B., and Kok, G. L.: Comparisons of in situ measurements of cirrus cloud ice water content, J. Geophys. Res., 112, D10212, doi:10.1029/2006JD008214, 2007b.

Forster, P., Ramaswamy, V., Artaxo, P., Berntsen, T., Betts, R., Fahey, D. W., Haywood, J., Lean, J., Lowe, D. C., Myhre, G., Nganga J., Prinn, R., Raga, G., Schulz, M., and Van Dorland, R.: Changes in Atmospheric Constituents and in Radiative Forcing, in: Climate Change 2007: The Physical Science Basis. Contribution of Working Group I to the Fourth Assessment Report of the Intergovernmental Panel on Climate Change, edited by: Solomon, S., Qin, D., Manning, M., Chen, Z., Marquis, M., Averyt, K. B., Tignor, M., and Miller, H. L., Cambridge University Press, Cambridge, United Kingdom and New York, NY, USA, 129-234, 2007.

Hallar, A. G., Avallone, L. M., Herman, R. L., Anderson, B. E., and Heymsfield, A. J.: Measurements of ice water content in tropopause region Arctic cirrus during the SAGE III Ozone Loss and Validation Experiment (SOLVE), J. Geophys. Res., 109, D17203, doi:10.1029/2003JD004348, 2004.
Heymsfield, A. J. and Donner, L. J.: A Scheme for Parameterizing Ice-Cloud Water Content in General Circulation Models, J. Atmos. Sci., 47, 1865-1877, 1990.

Heymsfield, A. J. and Platt, C. M. R.: A Parameterization of the Particle Size Spectrum of Ice Clouds in Terms of the Ambient Temperature and the Ice Water Content, J. Atmos. Sci., 41, 846$855,1984$.

Heymsfield, A. J., Winker, D., and van Zadelhoff, G. J.: Extinctionice water content-effective radius algorithms for CALIPSO, Geophys. Res. Lett., 32, L10807, doi:10.1029/2005GL022742, 2005.

Jensen, E., Starr, D., and Toon, O. B.: Mission investigates tropical cirrus clouds, EOS, 85, 45-50, 2004.

Jensen, E. J., Pfister, L., Bui, T.-P., Lawson, P., and Baumgardner, D.: Ice nucleation and cloud microphysical properties in tropical tropopause layer cirrus, Atmos. Chem. Phys., 10, 1369-1384, doi:10.5194/acp-10-1369-2010, 2010.

Kärcher, B. and Spichtinger, P.: Cloud-controlling Factors of Cirrus, Clouds in the Perturbed Climate System: Their Relationship to Energy Balance, Atmospheric Dynamics, and Precipitation (from the Strüngmann Forum Report), edited by: Heintzenberg, J. and Charlson, R. J., MIT Press, Cambridge, Massachusetts, USA, 235-267, 2009.

Krämer, M. and Afchine, A.: Sampling characteristics of inlets operated at low $\mathrm{U} / \mathrm{U}_{0}$ ratios: new insights from computational fluid dynamics (CFX) modeling, J. Aerosol Sci., 35, 683-694, doi:10.1016/j.jaerosci.2003.11.011, 2004.

Krämer, M., Schiller, C., Afchine, A., Bauer, R., Gensch, I., Mangold, A., Schlicht, S., Spelten, N., Sitnikov, N., Borrmann, S., de Reus, M., and Spichtinger, P.: Ice supersaturations and cirrus cloud crystal numbers, Atmos. Chem. Phys., 9, 3505-3522, doi:10.5194/acp-9-3505-2009, 2009.

Liou, K. N., Gu, Y., Yue, Q., and McFarquhar, G.: On the correlation between ice water content and ice crystal size and its application to radiative transfer and general circulation models, Geophys. Res. Lett., 35, L13805, doi:10.1029/2008GL033918, 2008.

Mace, G. G., Benson, S., and Vernon, E.: Cirrus Clouds and the Large-Scale Atmospheric State: Relationships Revealed by Six Years of Ground-Based Data, J. Climate, 19, 3257-3278, doi:10.1175/JCLI3786.1, 2006.

Mace, G. G., Clothiaux, E. E., and Ackerman, T. P.: The Composite Characteristics of Cirrus Clouds: Bulk Properties Revealed by One Year of Continuous Cloud Radar Data, J. Climate, 14, 21852203, 2001.

McFarquhar, G. M. and Heymsfield, A. J.: Parameterization of Tropical Cirrus Ice Crystal Size Distributions and Implications for Radiative Transfer: Results from CEPEX, J. Atmos. Sci., 54, 2187-2200, 1997.

Meyer, J., Baumgardner, D., Schnaiter, M., Möhler, O., Benz, S., Abdelmonem, A., Schmitt, C., Newton, R., Afchine, A., and Krämer, M.: Size spectra of ice and drops in mixed phase clouds: measurements with the novel cloud instrument NIXE-CAPS at the AIDA Cloud Chamber, in preparation for Atmos. Chem. Phys. Discuss., 2013.

Pan, L. L., Bowman, K. P., Atlas, E. L., Wofsy, S. C., Zhang, F., Bresch, J. F., Ridley, B. A., Pittman, J. V., Homeyer, C. R., Romashkin, P., and Cooper, W. A.: The Stratosphere-Troposphere Analyses of Regional Transport 2008 (START08) Experiment, B. Am. Meteorol. Soc., 91, 327-342, 2010. 
Rolf, C., Krämer, M., Schiller, C., Hildebrandt, M., and Riese, M.: Lidar observation and model simulation of a volcanicash-induced cirrus cloud during the Eyjafjallajökull eruption, Atmos. Chem. Phys., 12, 10281-10294, doi:10.5194/acp-1210281-2012, 2012.

Salzmann, M., Ming, Y., Golaz, J.-C., Ginoux, P. A., Morrison, H., Gettelman, A., Krämer, M., and Donner, L. J.: Two-moment bulk stratiform cloud microphysics in the GFDL AM3 GCM: description, evaluation, and sensitivity tests, Atmos. Chem. Phys., 10, 8037-8064, doi:10.5194/acp-10-8037-2010, 2010.

Sassen, K. and Campbell, J. R.: A Midlatitude Cirrus Cloud Climatology from the Facility for Atmospheric Remote Sensing. Part I: Macrophysical and Synoptic Properties, J. Atmos. Sci., 58, 481496, 2001.

Schiller, C., Krämer, M., Afchine, A., Spelten, N., and Sitnikov, N.: Ice Water Content of Arctic, midlatitude, and tropical cirrus, J. Geophys. Res., 113, D24208, doi:10.1029/2008JD010342, 2008.

Seifert, P., Ansmann, A., Mueller, D., Wandinger, U., Althausen, D., Heymsfield, A. J., Massie, S. T., and Schmitt, C.: Cirrus optical properties observed with lidar, radiosonde, and satellite over the tropical Indian Ocean during the aerosol-polluted northeast and clean maritime southwest monsoon, J. Geophys. Res., 112, D17205, doi:10.1029/2006JD008352, 2007.

Spichtinger, P. and Krämer, M.: Tropical tropopause ice clouds: A new approach to answer the mystery of low crystal numbers, Atmos. Chem. Phys. Discuss., 12, 28109-28153, doi:10.5194/acpd-12-28109-2012, 2012.
Stefanutti, L., Mackenzie, A. R., Santacesaria, V., Adriani, A., Balestri, S., Borrmann, S., Khattatov, V., Mazzinghi, P., Mitev, V., Rudakov, V., Schiller, C., Toci, G., Volk, C. M., Yushkov, V., Flentje, H., Kiemle, C., Redaelli, G., Carslaw, K. S., Noone, K., and Peter, T.: The APE-THESEO tropical campaign: An overview, J. Atmos. Chem., 48, 1-33, doi:10.1023/B:JOCH.0000034509.11746.b8, 2004.

Toon, O. B., Starr, D. O., Jensen, E. J., Newman, P. A., Platnick, S., Schoeberl, M. R., Wennberg, P. O., Wofsy, S. C., Kurylo, M. J., Maring, H., Jucks, K. W., Craig, M. S., Vasques, M. F., Pfister, L., Rosenlof, K. H., Selkirk, H. B., Colarco, P. R., Kawa, S. R., Mace, G. G., Minnis, P., and Pickering, K. E.: Planning, implementation, and first results of the Tropical Composition, Cloud and Climate Coupling Experiment (TC4), J. Geophys. Res., 115, D00J04, doi:10.1029/2009JD013073, 2010.

van Zadelhoff, G.-J., van Meijgaard, E., Donovan, D. P., Knap, W. H., and Boers, R.: Sensitivity of the shortwave radiative budget to the parameterization of ice crystal effective radius, J. Geophys. Res., 112, D08213, doi:10.1029/2006JD007791, 2007.

Vaughan, G., Schiller, C., MacKenzie, A. R., Bower, K., Peter, T., Schlager, H., Harris, N. R. P., and May, P. T.: SCOUTO3/ACTIVE: High-altitude aircraft measurements around deep tropical convection, B. Am. Meteorol. Soc., 89, 647-662, doi:10.1175/BAMS-89-5-647, 2008.

Wylie, D. P. and Menzel, W. P.: Eight Years of High Cloud Statistics Using HIRS, J. Climate, 12, 170-184, 1999. 